DOI:

\title{
Karakter Kesuburan Tanah di Lahan Pertanian Bekas Perladangan Berpindah
}

\section{Characteristics of Soil Fertility in Agricultural Land Former Moving Farms}

\author{
Riska Herlina ${ }^{1}$ La Karimuna $^{2^{*}}$ Harjoni Kilowasid $^{2}$ La Ode Santiaji Bande ${ }^{2}$ Rachmawati Hasid $^{2}$ Jamili $^{2}$ \\ ${ }^{1}$ Mahasiswa Jurusan Agronomi Program Pascasarjana Universitas Halu Oleo \\ ${ }^{2}$ Dosen Jurusan Agronomi Program Pascasarjana Universitas Halu Oleo \\ Jl. Mayjend S. Parman Kel. Kemaraya Kendari, 93121, Indonesia
}

Diterima: 22 Maret 2019/Disetujui: 15 Mei 2019

\begin{abstract}
Characteristics of soil fertility on former shifting cultivation. This study aims to determine the physical and chemical properties of soil from former shifting cultivation in Muna District, Southeast Sulawesi Province. This type of research is a survey study using a plot method of 8 plots randomly placed on ex-shifting cultivation by taking soil samples in each plot for analysis of the physical and chemical properties of the soil. The physical properties of soil include soil texture and soil chemistry including soil pH, total N, P-available, C-Organic, CEC, Ca and Mg. This research was carried out in the village of Katobu, Wakontu in Wadaga District and Halu Oleo University Soil Science Laboratory from July to October 2017. The results showed that the results of laboratory analysis of soil texture from former shifting cultivation in Katobu village for plot 1 with texture sandy clay, plots 2 and 3 with clay textures, plots 4 to 8 with a dust texture. As for the soil texture of former shifting cultivation in Wakontu village for plot 1 with clay-textured soil, plot 2 to plot 8 with a dust texture. The results of the analysis of the chemical properties of soil from former shifting cultivation from Katobu village for average $\mathrm{pH}$ were $6.64, \mathrm{~N}$-Total averaged $0.242 \%, P$-Available averaged $2.593 \mathrm{ppm}$, average CEC was $27,516 \mathrm{cmol} / \mathrm{kg}$, C-Organic averaged $0.756 \%$, the average Ca was $16.544 \mathrm{cmol} / \mathrm{kg}$ and the average $\mathrm{Mg}$ was $16.544 \mathrm{cmol} / \mathrm{kg}$. while for the chemical properties of soil from ex-shifting cultivation land in Wakontu village, the average soil $\mathrm{pH}$ was 6.41, N-Total averaged 0.224\%, P-Available averaged $2477 \mathrm{ppm}$, mean CEC was $6.609 \mathrm{cmol} / \mathrm{kg}$, C-Organic averages $0.789 \%$, average $\mathrm{Ca}$ is $134.080 \mathrm{cmol} / \mathrm{kg}$ and average $\mathrm{Mg}$ is $15.067 \mathrm{cmol} / \mathrm{kg}$.
\end{abstract}

Keywords: Switching cultivation land, physical and chemical properties of soil

ABSTRAK

Karakter kesuburan tanah di lahan pertanian bekas perladangan berpindah.Penelitian ini bertujuan untuk mengetahui sifat fisik dan kimia tanah dari lahan pertanian bekas perladangan berpindah di Kabupaten Muna Provinsi Sulawesi Tenggara. Jenis penelitian ini merupakan penelitian survei dengan menggunakan metode plot sebanyak 8 plot yang diletakkan secara acak pada lahan bekas perladangan berpindah dengan mengambil sampel tanah pada masingmasing plot untuk dilakukan analisis mengenai sifat fisik dan kimia tanah. Sifat fisik tanah meliputi tekstur tanah dan kimia tanah meliputi pH tanah, N-total, P-tersedia, C-Organik, KTK, Ca dan Mg. Penelitian ini dilaksanakan di desa Katobu, Wakontu di Kecamatan Wadaga dan Laboratorium Jurusan Ilmu Tanah Universitas Halu Oleo dari bulan Juli sampai bulan Oktober 2017. Hasil penelitian menujukkan bahwa hasil analisis laboratorium mengenai tekstur tanah dari lahan bekas perladangan berpindah di desa Katobu untuk plot 1 dengan tekstur liat berpasir, plot 2 dan 3 dengan tekstur lempung, plot 4 sampai 8 dengan tekstur debu. Sedangakan untuk tekstur tanah dari lahan bekas perladangan berpindah di desa Wakontu untuk plot 1 dengan tanah bertekstur liat, plot 2 sampai plot 8 dengan tekstur debu. Hasil analisis mengenai sifat kimia tanah dari lahan bekas perladangan berpindah dari desa Katobu untuk $\mathrm{pH}$ rata-rata tahah yaitu 6,64, N-Total rata-rata yaitu $0,242 \%$, P-Tersedia rata-rata $2,593 \mathrm{ppm}$, KTK rata-rata yaitu $27,516 \mathrm{cmol} / \mathrm{kg}$, C-Organik rata-rata yaitu $0,756 \%$, Ca ratarata yaitu $16,544 \mathrm{cmol} / \mathrm{kg}$ dan $\mathrm{Mg}$ rata-rata yaitu $16,544 \mathrm{cmol} / \mathrm{kg}$. sedangkan untuk sifat kimia tanah dari lahan bekas

\footnotetext{
* Penulis untuk korespondensi, e-mail: lkarimuna@hotmail.com
} 


\section{J. Berkala Penelitian Agronomi 7 (1) : 1 - 6 (2019)}

perladangan berpindah di desa Wakontu untuk $\mathrm{pH}$ tanah rata-rata yaitu 6,41, N-Total rata-rata yaitu 0,224 \%, P-Tersedia rata-rata $2477 \mathrm{ppm}$, KTK rata-rata yaitu $6,609 \mathrm{cmol} / \mathrm{kg}$, C-Organik rata-rata yaitu 0,789 \%, Ca rata-rata yaitu 134,080 $\mathrm{cmol} / \mathrm{kg}$ dan Mg rata-rata yaitu $15,067 \mathrm{cmol} / \mathrm{kg}$.

Kata Kunci: Lahan Perladangan Berpindah, Sifat Fisik dan Kimia Tanah

\section{PENDAHULUAN}

Sistem perladangan berpindah merupakan salah satu kegiatan penggunaan lahan yang banyak dilakukan oleh petani tradisional di Indonesia (Sulistiawati et al., 2005).Sistem ini digunakan untuk menggambarkan suatu sistem penggunaan lahan yang melibatkan fase tanam atau produksi dan masa bera yaitu masa dimana vegetasi berkembang secara suksesi alami. Suksesi dari vegetasi di lahan budidaya yang diberakan akan mengalami tahapan regenerasi lebih cepat selama masa bera dibandingkan dengan lahan yang dibudidayakan secara terus-menerus. Parameter vegetasi yang dapat dilihat yaitu struktur tajuk dari kanopi dan keanekaragaman jenis pohon penyusun ekosistem yang hampir menyerupai ekosistem hutan (Karthik et al., 2009).

Beberapa daerah di Indonesia yang juga mempraktekkan sistem perladangan berpindah yaitu masyarakat Baduy Provinsi Banten Selatan. Kegiatan perladangan dikenal dengan istilah ngahuma yaitu sistem berladang dengan menanam padi ladang, dengan mengkombinasikan berbagai jenis tanaman pohon maupun jenis tanaman pertanian lainnya. Kegiatan berladang dilakukan sekali dalam setahun kemudian diistrahatkan selama 5 tahun (Senoaji, 2012). Selain itu, masyarakat DayakMeratus Loksado Provinsi Kalimantan Selatan melakukan kegiatan perladangan berpindah yang dikenal dengan istilah gilir balik yaitu bentuk kearifan lokal dari kegiatan perladangan yang lahir dari tradisi dan pengalaman masyarakat Dayak Meratus Loksado. Lahan ditanami Oryza sativa sebagai tanaman pokok sedangkan tanaman semusim berupa Arachis hypogaea L., Amaranthus sp., Zea mays, Manihot utilisima L., Musa paradisiata L., dan tanaman tahunan berupa Hevea brasiliensis Muell, Arg, Cinnamomum verum dan Aleurites moluccana. Masa tanam 1-2 tahun kemudian diistrahatkan 2-7 tahun (Asyisifa, 2009).

Di Negara Asia Tenggara beberapa negara yang mempraktekkan sistem perladangan berpindah yaitu Thailand yang hasil pertaniannya untuk konsumsi rumah tangga dengan komoditas utama yaitu Oryza sativa tetapi mengalami pergeseran sehingga masyarakat mulai menanam Oryzasp yang dikombinasikan dengan tanaman semusim seperti Zea mays, Triticum ssp, Capsicum anпиит L., Arachis hypogaea L. dan Gossypium sp. Ladang ditanami 1-2 tahun kemudian setelah masa produksi berakhir lahan kemudian diberakkan selama 12 sampai 17 tahun.Sedangkan di negara Vietnam para petani menerapkan perladangan berpindah dengan sistem agroforestri dengan menanam Oriza sp sebagai komoditas utama. Setelah produksi, ladang kemudian ditanami tanaman kehutanan dengan komposisi vegetasi seperti Mangletia glauca, Styrax tonkinensis, Cinnamomum cassia, Pinus merkusii, Illicium verum, Acacia mangium, Cunninghamia sinensis, Pinus khesiya, Eucalyptus spp, Acacia auriculiformis, Tectona grandis, Dipterocarpus alatus, Anisoptera cochinchinensis, Canarium spp, Talaunna gioi dan Cassia sianea (Vogh, 2001).

Kabupaten Muna merupakan salah satu daerah di Provinsi sulawesi Tenggara yang melakukan kegiatan perladangan dengan membuka lahan hutan untuk dijadikan lahan pertanian. Kegiatan perladangan ini sudah dilakukan oleh petani sejak zaman nenek moyang terdahulu. Petani awalnya menanamtanamanbudidaya untuk memenuhi kebutuhan pangan keluarga serta dijual untuk menambah penghasilan. Setelah 1-2 tahun masa tanam berakhir petani meninggalkan lahan tersebut, tetapi sebelum meninggalkan lahan petani menanam tanaman jangka panjang sebagai bukti kepemilikan lahan. Lahan diistrahatkan dengan tujuan untuk memulihkan kesuburan tanah.Hal ini dilakukan karena masyarakat dalam bercocok tanam tidak menggunakaan pupuk tetapi dari hasil pemulihan lahan bekas perladangan.

Masyarakat menanam tanaman utama seperti Manihot utilisima, Zea mays, Arachis hypogaea L. dilahan mereka untuk memenuhi kebutuhan pangan keluarga, tetapi setelah dirasakan hasil produksi dari tanaman sudah mengalami penurunan, masyarakat mulai mencari lahan baru yang masih produktif untuk dibudidayakan. Pada perkembangannya lahan bekas 
perladangan berpindah yang sudah tidak pernah digarap lagi tanahnya akan semakin subur dan membentuk kumpulan dari berbagai vegetasi mulai tumbuhan pionir hingga tumbuhan yang tumbuh sendiri selama tahapan suksesi terjadi sehingga membentuk keanekaragaman penyusun lahan bekas perladangan berpindah.

Keanekaragaman dalam suatu ekosistem dapat memiliki efek stabilisasi. Perubahan lingkungan yang terjadi dalam suatu ekosistem akan membuat mereka menjadi lebih toleran terhadap stres dan lebih cepat beradaptasi untuk dapat bertahan hidup (European, 2015). Keanekaragaman vegetasi tumbuhan dalam suatu ekosistem akan memberikan peranan penting bagi masyarakat dan lingkungan kaitannya dengan penyediaan jasa ekosistem yang diberikan (Yapp et al., 2015). Peranan keanekaragaman tumbuhan dalam fungsi dan penyediaan layanan jasa ekosistem pada suatu lahan dalam hal peningkatan kualitas tanah, pengolahan unsur hara (Yapp et al., 2015).

Berdasarkan uraian latar belakang tersebut sehingga penulis tertarik untuk melakukan penelitian mengenai karakter kesuburan tanah di bekas perladangan berpindah dengan tujuan untuk mengetahui sifat fisik dan kimia tanah dari lahan bekas perladangan berpindah di desa Katobu dan Wakontu.

\section{METODE PENELITIAN}

Penelitian ini dilakukan pada lahan pertanian bekas perladangan berpindah di desa Katobu dan Wakontu Kecamatan Wadaga Kabupaten Muna
Provinsi Sulawesi Tenggara.Topografi dari lokasi penelitian merupakan dataran rendah. Curah hujan rata-rata 122,39 , temperatu rata-rata $28-30{ }^{\circ} \mathrm{C}$ dan kelembaban rata-rata 76,00.

Bahan yang digunakan dalam penelitian iniadalah tanah sebagai sampel penelitian,dan bahanbahan kimia untuk keperluan analisis sampel tanah sedangkan alat yang digunakan yaitu kamera, meteran rol, meteran kain, GPS, tali rafia, patok, parang, kantong plastik, kertas label, seloktip, ring tanah, alat tulis menulis, termometer, lux meter, dan alat-alat untuk analisis sampel tanah.

Pengambilan sampel tanah dilakukan menggunakan ring sampel dengan kedalaman 0 - 10 $\mathrm{cm}$. Tanah yang akan dijadikan sampel diambil pada lima titik yaitu di tiap ujung dari plot dan bagian tengah dari plot kemudian tanah tersebut dikompositkan. Sampel yang telah dikompositkan kemudian dimasukkan ke dalam kantong sampel dan diberi label.

Teknik pengumpulan data sampel tanah meliputi $\mathrm{pH}$ dengan metode elektroda glass, tekstur tanah dengan metode pipet, C-Organik dengan metode Walkley \& Black, N-total dengan metode Kjeldahl, P-tersedia dengan Ekstraksi Bray, Ca dan Mg dengan metode ekstrak Morgan Wolf, KTK.

\section{HASIL DAN PEMBAHASAN}

Hasil analisis tekstur tanah di lahan pertanian bekas perladangan berpindah desa Katobu dan Wakontu disajikan secara rinci pada Tabel 1 dan 2 .

Tabel 1. Hasil Analisis Laboratorium terhadap Tekstur Tanah di Lahan Pertanian Bekas Perladangan Berpindah Desa Katobu Kecamatan Wadaga

\begin{tabular}{cccccl}
\hline \multirow{2}{*}{$\begin{array}{c}\text { Desa } \\
\text { Katobu }\end{array}$} & \multirow{2}{*}{$\begin{array}{c}\text { Kedalaman } \\
(\mathbf{c m})\end{array}$} & \multicolumn{4}{c}{ Parameter Sifat Fisik Tanah } \\
\cline { 3 - 6 } & & \% Pasir & \% Debu & \% Liat & \multicolumn{1}{c}{ Tekstur } \\
\cline { 3 - 6 } & $0-10$ & 45,4073 & 44,7592 & 9,8335 & Liat Berpasir \\
K.1 & $0-10$ & 22,7943 & 56,2124 & 20,9933 & Lempung \\
K.2 & $0-10$ & 34,7245 & 54,32 & 10,9555 & Lempung \\
K.3 & $0-10$ & 33,0869 & 55,871 & 11,0422 & Debu \\
K.4 & $0-10$ & 14,7689 & 82,3675 & 2,8636 & Debu \\
K.5 & $0-10$ & 23,9154 & 64,8946 & 11,19 & Debu \\
K.6 & $0-10$ & 31,1899 & 58,6273 & 10,1828 & Debu \\
K.7 & $0-10$ & 51,5911 & 51,5911 & 8,7507 & Debu \\
K.8 & $0-10$ & & & &
\end{tabular}

Hasil analisis tekstur tanah pada lahan pertanian bekas perladangan berpindahdi desa Katobu menunjukkan bahwa tekstur tanah pada plot 1 termasuk dalam tekstur liat berpasir, plot 2 dengan 
tekstur lempung, plot 3 bertekstur lempung dan

untuk plot 4 sampai 8 bertekstur debu.

Tabel 2. Hasil Analisis Laboratorium terhadap Tekstur Tanah di Lahan Pertanian Bekas Perladangan Berpindah Desa Wakontu Kecamatan Wadaga

\begin{tabular}{cccccc}
\hline \multirow{2}{*}{$\begin{array}{c}\text { Desa } \\
\text { Wakontu }\end{array}$} & \multirow{2}{*}{$\begin{array}{c}\text { Kedalaman } \\
(\mathbf{c m})\end{array}$} & \multicolumn{4}{c}{ Parameter Sifat Fisik Tanah } \\
\cline { 3 - 6 } & & \% Pasir & \% Debu & \% Liat & Tekstur \\
\hline W.1 & $0-10$ & 29,3352 & 59,4582 & 11,2066 & Liat \\
W.2 & $0-10$ & 42,8295 & 44,33 & 12,8404 & Debu \\
W.3 & $0-10$ & 28,2717 & 57,6102 & 14,1181 & Debu \\
W.4 & $0-10$ & 41,5689 & 46,2298 & 12,2013 & Debu \\
W.5 & $0-10$ & 29,4745 & 58,5673 & 11,9582 & Debu \\
W.6 & $0-10$ & 41,9228 & 47,4416 & 10,6356 & Debu \\
W.7 & $0-10$ & 40,4199 & 47,1062 & 12,4739 & Debu \\
W.8 & $0-10$ & 30,2322 & 60,2576 & 9,5102 & Debu \\
\hline
\end{tabular}

Hasil analisis tekstur tanah pada lahan pertanian bekas perladangan berpindahdi desa Wakontu menunjukkan bahwatekstur tanah pada plot
2 sampai plot 8 termasuk dalam tekstur debu, sedangkan plot 1 termaksud dalam tekstur lia.

Tabel 3. Hasil Analisis Sifat Kimia Tanah Pada Lahan Pertanian Bekas Perladangan Berpindah di Desa Wakontu Kecamatan Wadaga

\begin{tabular}{|c|c|c|c|c|c|c|c|}
\hline \multirow[b]{2}{*}{$\begin{array}{c}\text { Desa } \\
\text { Katobu }\end{array}$} & \multicolumn{7}{|c|}{ Parameter Pengamatan } \\
\hline & pH & $\begin{array}{c}\mathrm{N}- \\
\text { total } \\
(\%)\end{array}$ & $\begin{array}{c}\mathbf{P}- \\
\text { tersedia } \\
(\mathbf{p p m})\end{array}$ & $\begin{array}{c}\text { KTK } \\
(\mathrm{cmol} / \mathrm{kg})\end{array}$ & $\begin{array}{c}\mathrm{Ca} \\
(\mathrm{cmol} / \mathrm{kg})\end{array}$ & $\begin{array}{c}\mathrm{Mg} \\
(\mathrm{cmol} / \mathrm{kg})\end{array}$ & $\begin{array}{c}\text { C- } \\
\text { organik } \\
(\%)\end{array}$ \\
\hline K.1 & 6,66 & 0,280 & 2,578 & 39,920 & 38,569 & 17,052 & 0,703 \\
\hline K.2 & 6,47 & 0,293 & 2,627 & 29,918 & 36,426 & 16,104 & 0,682 \\
\hline K.3 & 6,73 & 0,224 & 2,766 & 53,050 & 39,340 & 17,393 & 0,679 \\
\hline K.4 & 6,67 & 0,233 & 2,608 & 27,017 & 32,783 & 14,494 & 0,758 \\
\hline K.5 & 6,83 & 0,197 & 2,691 & 21,573 & 40,143 & 17,748 & 0,561 \\
\hline K.6 & 6,65 & 0,227 & 2,554 & 12,630 & 37,113 & 16,408 & 0,902 \\
\hline K.7 & 6,57 & 0,231 & 2,485 & 12,243 & 38,569 & 17,052 & 0,922 \\
\hline K. 8 & 6,56 & 0,253 & 2,436 & 23,775 & 36,426 & 16,104 & 0,841 \\
\hline Rerata & $\begin{array}{c}\mathbf{6 , 6 4} \\
\text { (Netral) }\end{array}$ & $\begin{array}{c}0,242 \\
(\mathrm{~S})\end{array}$ & $\begin{array}{c}2,593 \\
\text { (SR) }\end{array}$ & $\begin{array}{c}27,516 \\
(\mathrm{~T})\end{array}$ & $\begin{array}{c}37,421 \\
(\mathrm{ST})\end{array}$ & $\begin{array}{c}16,544 \\
(\mathrm{~T})\end{array}$ & $\begin{array}{l}0,756 \\
(\mathrm{SR})\end{array}$ \\
\hline
\end{tabular}

Keterangan : $\mathrm{ST}=$ sangat tinggi, $\mathrm{SR}=$ sangat rendah, $\mathrm{S}=$ sedang, $\mathrm{T}=$ tinggi

Hasil analisis sifat kimia tanah pada lahan pertanian bekas perladangan berpindah di desa Katobu pada kedalaman masing-masing $10 \mathrm{~cm}$ bahwa parameter $\mathrm{pH}$ tanah rata-rata dari plot 1-8 yaitu 6,64. Nitrogen (N-total) rata-rata pada plot 1-8 yaitu $0,242 \%$. P-tersedia rata-rata pada plot 1-8 yaitu 2,593 ppm. Kapasitas tukar kation (KTK) ratarata pada plot $1-8$ yaitu $27,516 \mathrm{cmol} / \mathrm{kg}$. Kalsium (Ca) rata-rata pada plot $1-8$ yaitu $37,421 \mathrm{cmol} / \mathrm{kg}$. Magnesium $(\mathrm{Mg})$ rata-rata pada plot 1-8 yaitu 16,544 $\mathrm{cmol} / \mathrm{kg}$ dan kandungan $\mathrm{C}$-organik tanah rata-rata pada plot 1-8 yaitu $0,756 \%$. 
Tabel 4. Hasil Analisis Sifat Kimia Tanah Pada Lahan Pertanian Bekas Perladangan Berpindah di Desa Wakontu Kecamatan Wadaga

\begin{tabular}{cccccccc}
\hline \multirow{2}{*}{$\begin{array}{c}\text { Desa } \\
\text { Wakontu }\end{array}$} & $\mathbf{p H}$ & \begin{tabular}{c}
$\mathbf{N}-$ \\
total \\
\cline { 2 - 8 }
\end{tabular} & $\begin{array}{c}\text { P- } \\
\text { tersedia } \\
(\mathbf{p p m})\end{array}$ & $\begin{array}{c}\text { KTK } \\
(\mathbf{c m o l} / \mathbf{k g})\end{array}$ & $\begin{array}{c}\mathbf{C a} \\
(\mathbf{c m o l} / \mathbf{k g})\end{array}$ & $\begin{array}{c}\mathbf{M g} \\
(\mathbf{c m o l} / \mathbf{k g})\end{array}$ & $\begin{array}{c}\mathbf{C}- \\
\text { Organik } \\
(\mathbf{\%})\end{array}$ \\
\hline W.1 & 6,53 & 0,202 & 2,423 & 28,154 & 31,726 & 14,026 & 0,752 \\
W.2 & 6,47 & 0,250 & 2,622 & 1,196 & 32,783 & 14,494 & 0,792 \\
W.3 & 6,38 & 0,234 & 2,626 & 0,286 & 35,125 & 15,529 & 0,901 \\
W.4 & 6,22 & 0,241 & 2,534 & 9,478 & 33,914 & 14,994 & 0,666 \\
W.5 & 6,71 & 0,244 & 2,590 & 0,317 & 35,125 & 15,529 & 0,947 \\
W.6 & 6,36 & 0,265 & 2,395 & 3,174 & 36,426 & 16,104 & 0,683 \\
W.7 & 6,26 & 0,166 & 2,425 & 9,632 & 33,914 & 14,994 & 0,839 \\
W.8 & 6,33 & 0,192 & 2,201 & 0,632 & 33,624 & 14,866 & 0,733 \\
\hline Rerata & $\mathbf{6 , 4 1}$ & $\mathbf{0 , 2 2 4}$ & $\mathbf{2 , 4 7 7}$ & $\mathbf{6 , 6 0 9}$ & $\mathbf{3 4 , 0 8 0}$ & $\mathbf{1 5 , 0 6 7}$ & $\mathbf{0 , 7 8 9}$ \\
& $(\mathbf{N e t r a l})$ & $\mathbf{( S )}$ & $\mathbf{( S R )}$ & $\mathbf{( S R )}$ & $\mathbf{( S T )}$ & $\mathbf{( T )}$ & $\mathbf{( S R )}$ \\
\hline
\end{tabular}

Keterangan : $\mathrm{ST}=$ sangat tinggi, $\mathrm{SR}=$ sangat rendah, $\mathrm{S}=$ sedang, $\mathrm{T}=$ tinggi

Hasil analisis sifat kimia tanah pada lahan pertanian bekas perladangan berpindah di desa Wakontu pada kedalaman masing-masing $10 \mathrm{~cm}$ bahwa parameter $\mathrm{pH}$ tanah rata-rata pada plot 1-8 yaitu 6,41. Nitrogen (N-total) rata-rata pada plot 1-8 yaitu $\quad 0,224 \%$. P-tersedia rata-rata pada plot 1-8 yaitu 2,477 ppm. Kapasitas tukar kation (KTK) ratarata pada plot $1-8$ yaitu $6,609 \mathrm{cmol} / \mathrm{kg}$.Kalsium (Ca) rata-rata pada plot $1-8$ yaitu $34,080 \mathrm{cmol} / \mathrm{kg}$. Magnesium (Mg) rata-rata pada plot 1-8 yaitu 15,067 $\mathrm{cmol} / \mathrm{kg}$ dan kandungan C-organik tanah rata-rata pada plot 1-8 yaitu $0,789 \%$.

\section{PEMBAHASAN}

Karakter kesuburan tanah di lahan pertanian bekas perladangan berpindah di desa Katobu dan Wakontu untuk sifat fisik tanah dalam hal tekstur tanah dan sifat kimia tanah meliputi $\mathrm{pH}, \mathrm{N}$-Total, PTersedia, KTK, C-Organik, Ca dan Mg. Tekstur tanah adalah perbandingan partikel pasir, debu dan liat. Kemampuan tanah dalam menghantarkan dan menyimpan air, menyediakan dan menyimpan hara bagi tanaman (Hanafiah, 2005).Tekstur tanah dari lahan pertanian bekas perladangan berpindah didesa Katobu untuk plot 1 termasuk dalam tekstur liat berpasir, plot 2 dan 3 bertekstur lempung sedangkan untuk plot 4-8 bertekstur debu. Menurut Hanafiah (2005), tekstur tanah debu dan lempung mempunyai kemampuan ketersediaan yang optimum untuk tanaman namun tanah lempung lebih baik dalam menyimpan nutrisi dibandingkan tanah bertekstur debu. Untuk tekstur tanah dari lahan pertanian bekas perladangan berpindah didesa Wakontu pada plot 1 termasuk dalam kategori liat sedangkan tekstur tanah pada plot 2-8 bertekstur debu. Tanah dengan tekstur liat memiliki luas permukaan yang lebih besar sehingga dalam menyediakan unsur hara bagi tanamana lebih tinggi (Hardjowigeno, 2003).

Hasil analisis kimia tanah pada lahan pertanian bekas perladangan berpindah di desa Katobu dan Wakontu sangat berfariasi untuk setiap plot pengamatan.Untuk menunjang pertumbuhan suatu tanaman, sifat kimia tanah memegang peranan yang sangat penting salah satunya merupakan sifat penentu dari tingkat kesuburan tanah.Hasil analisis pH tanah pada lahan pertanian bekas perladangan berpindah di dua desa tergolong dalam kategori netral yaitu antara 6,643-6,408 yang merupakan $\mathrm{pH}$ normal untuk pertumbuhan tanaman.Menurut Foth (1998) dalam Kirnandi et al., (2014) secara umum pH tanah memberikan pengaruh besar terhadap pertumbuhan tanaman kaitannya dengan ketersediaan unsur hara dalam tanah.

Kandungan unsur hara $\mathrm{N}$-total dalam tanah di lahan pertanian bekas perladangan berpindah untuk desa Katobu dan Wakontu rata-rata 0,242-0,224 \% masuk dalam kategori sedang.Kandungan unsur Ptersedia dalam tanah untuk desa Katobu dan Wakontu 
rata-rata $\quad 2,593-2,477$ ppm masuk dalam kategori sangat rendah. Kapasitas tukar kation (KTK) tanah pada lahan pertanian bekas perladangan berpindah desa Katobu dan Wakontu rata-rata 27,516-6,609 $\mathrm{cmol} / \mathrm{kg}$ masuk dalam tinggi untuk desa Katobu, rendah untukdesa Wakontu. Kandungan C-Organik tanah di dua desa rata-rata $\quad 0,756-0,789 \%$ masuk dalam kategori sangat rendah, kandungan unsur Ca rata-rata 34,080-37,421 cmol/kg termasuk kategori sangat tinggi dan $\mathrm{Mg}$ rata-rata 15,067-16,544 cmol/kg masuk dalam kategori tinggi. Keberadaan lahan pertanian bekas perladangan berpindahsebagai suatu sistem perladangan yang telah di lakukan secara turun-temurun oleh masyarakat etnis Muna, berdasarkan hasil analisis tanah di dua desa meliputi kandungan unsur hara Ntotal, P-tersedia, KTK, C-Organik, Ca dan Mg yang baik dari hasil daur ulang nutrisi untuk pertumbuhan tanaman. Lahan pertanian bekas perladangan berpindahdi desa Katobu dan Wakontu memiliki masa bera yang cukup lama setelah diolah dengan umur \pm 50 tahun, dimana lamanya masa bera dari lahan pertanian bekas perladangan berpindahakan memulihkan komposisi tumbuhan penyusunnya dan mendaur ulang nutrisi dari sisa-sisa organ tumbuhan seperti serasah, ranting dan buah yang jatuh ke dasar hutan. Jean et al., (2006) masa bera dapat memulihkan vegetasi tumbuhan baik yang sengaja ditanaman maupun tumbuhan yang tumbuh selama tahap suksesi berlangsung dan untuk mengembalikan kesuburan tanah.

\section{KESIMPULAN}

Karakter sifat fisik dan kimia tanah dari lahan pertanian bekas perladangan berpindah melihat sifat fisik yaitu tekstur tanahdesa Katobu dari liat berpasir, lempung dan debu dandesa Wakontu kelas tekstur tanahnya dari liat dan debu.Kimia tanah di dua desa yaitu rata-rata nilai $\mathrm{pH}$ tanah netral, $\mathrm{N}$-total dari sedang sampai sangat rendah, P-tersedia sangat rendah, KTK dari tinggi, sedang dan sangat rendah, C-Organik sangat rendah, Ca sangat tinggi dan $\mathrm{Mg}$ tinggi.

\section{DAFTAR PUSTAKA}

Asysyifa, 2009.Karakteristik Sistem Perladangan Suku Dayak Meratus Kecamatan Loksado
Kalimantan Selatan.Jurnal Hutan Tropis Borneo.No. 25 Maret 2009 : 98-109.

European Commission, 2015.Ecosystem Service and Biodiversity, Science for Environmental Polisy.

Hanafiah K.A. 2005. Dasar-Dasar Ilmu Tanah, Raja Grafindo Persada, Jakarta.

Hardjowigeno S. 2003. Klasifikasi Tanah dan Pedogenesis. Akademik Pressindo. Jakarta.

Jean, Makuna R. and Thomas S.C. 2006. Impact of Selective Logging and Agriculture Clearing on Forest Structure, Floristick Composition and diversity, and Timber Tree Regeneration in the Ituri Forest, Dencratic Republik of Congo, Biodiversity and

Conservation, 15 (2006): 1375-1397.

Karthik T. Veeraswani G.G. and Samal P.K. 2009.Forest Recovery Following Shifting Cultivation: On Overview of Existing Research, Tropical Coservation Science, Vol. 2 (4): 374-378.

Kirnandi, A.J., A. Zuraida dan Ilhamiyah, 2014. Survei Status Kesuburan Tanah di Lahan Padi Sawah Pasang Surut Kabupaten Banjar.Media Sains.Vol. 7(1): 54-60.

Senoaji G. 2012. Pengelolaan Lahan Dengan Sistem Agroforestri oleh Masyarakat Baduy di Banten Selatan, Jurnal Bumi Lestari.Vol. 12 (2): 283-293.

Sulistiawaty E. NobleI.R.dan Rederick M.L. 2005.Asimulation Model to Study Land Use Strategies in Swidden Agriculture Systems. Agriculture System 5 (2005): 271-288.

Vogh D. and Schmidt, 2001. Secondary Forest in Swidden Agriculture in The High Land of Thailand. Journal of Tropical Forest Science, Vol. 13 (4): 748-767.

Yapp A.G., andThackwayR., 2015. Responding to Change-Criteria and Indikator for Managing The Transformation of Vegetated Landscapes to Maintain Restore Ecosystem Diversity. Biodiversity in Ecosystem Link Structure and Function: 123-153. 